\title{
OCCUPATIONAL HEALTH AND SAFETY MANAGEMENT SYSTEM (OHSMS) MODEL FOR CONSTRUCTION INDUSTRY
}

\author{
A.S.Ligade ${ }^{1}$, S.B.Thalange ${ }^{2}$ \\ ${ }^{\text {I} D e p a r t m e n t ~ o f ~ C i v i l ~ E n g i n e e r i n g, ~ A . G ~ P a t i l ~ I n s t i t u t e ~ o f ~ T e c h n o l o g y, 18 / 2 / 1 A, ~ p r a t a p ~ n a g a r, ~ O p p . S R P ~ C a m p, ~ V i j a p u r ~}$ \\ Road, Solapur 413008, Maharashtra, India: anil.sssp@gmail.com \\ ${ }^{2}$ Department of Civil Engineering, Walchand Institute of Technology, P.B.No.634, Walchand Hirachand Marg, Ashok \\ Chowk, Solapur 413006, Maharashtra, India: thalange.satish@gmail.com
}

\begin{abstract}
The objective of this study is to imperative that the Construction is a high risk industry for clients, contractors and workers alike. Construction business is considered to be successful only when it constructs safe structures and provides safe working environment. An application of OHSMS Model in construction industry will achieve the accomplishment of safety at site, absence of danger at work which is made possible by eliminating the job hazards that create the danger. It will also, however inform workers and supervisors of the essentials of a proper occupational health and safety management system. Accident records and cost is an important aspect for promotion of OHSMS model. The previous informative data provides the base for economic analysis and developments to avoid accidents. OHSMS Model of OHSAS: 18001 certification provides a route to continuous improvement for organization by assisting with implementation of the OHSMS Model for construction industry. Study is related to MICL, Mumbai for their project named "Civil Works for Construction of Residential Project Using Mivan Shuttering for 12 Towers" in Blue Ridge project area, Hinjewadi, Pune.
\end{abstract}

Keywords: OHSMS Systems, OSH certification process, need of OHSAS 18001, OHSMS Model Requirements, Use of PDCA Cycle, safety and cost relationship.

\section{INTRODUCTION}

Construction sites in developing countries are 10 times more dangerous than in industrialized nations and the fatality rate in developed countries is almost half of that in India and an estimated 1580 workers per one lakh in this sector. So; the basic learning process about hazard and risk reduction is at the root of the more sophisticated principles governing today's Occupational Health and Safety. The modern safety moment started around 1912 with the first cooperative safety congress and the organization of the safety council in USA. From 1912 to the present time, remarkable advances have been made in reducing the rate of severity of the accidents. The importance of safety was realized because every year million of construction/ industrial accidents occur which results in death or temporary and prominent disablement of the employees and involve good amount of cost such as resulting from wasted man-hours etc.[1] Broadly, an ideal occupational health and Safety Management System (OHSMS) should provide a structured process to minimize potentials of work related injuries and illnesses, increases productivity by reducing direct and indirect costs associated with accidents.[6]

\section{OCCUPATIONAL HEALTH AND SAFETY}

\section{MANAGEMENT SYSTEMS}

There are a number of Occupational Health and Safety management systems which can be applied including the HSE Guidance Booklet HS(G)65 "Successful Health and Safety Management", the British Standard BS OHSAS 18001: 2007 "Occupational Health and Safety Management SystemsRequirements" and the International Labour Office ILO-OSH 2001 "Guidelines on Occupational Safety and Health Management systems".[7] Each of these management systems is based on the "plan-do-check-act" Management Model and embodies the principle of continual improvement.

\section{A. Concept of PDCA Cycle [6]}

This concept of a process is based on the principle of the "plan-do-check-act" cycle (PDCA) to monitor performance of a construction organisation on a continual basis. When applied to $\mathrm{OSH}$,

a) PLAN- Involves the setting of an OSH Policy, Planning including the allocation of resources, provision of skills and organization of the system, hazard identification and risk assessment.

b) DO- Refer to actual implementation and operation of the OSH programme. 
c) CHEAK- Step is devoted to measuring both the active and reactive performance of the programme.

d) ACT-Step closes the cycle with a review of the system in the context of continual improvement and the priming of the system for the next cycle.

\section{B. OHSAS 18001: 2007 OHSMS}

The OHSAS standards covering Occupational Health and Safety Management are intended to provide organization with the elements of an effective OHSMS that can be integrated with other management requirements and help construction organisations to achieve Occupational Health and Safety and Economic Objectives. This OHSAS standard specifies requirements for an OHSMS to enable an construction organization to develop and implement a policy and objectives which take into account legal requirements and information about Occupational health and Safety risks.

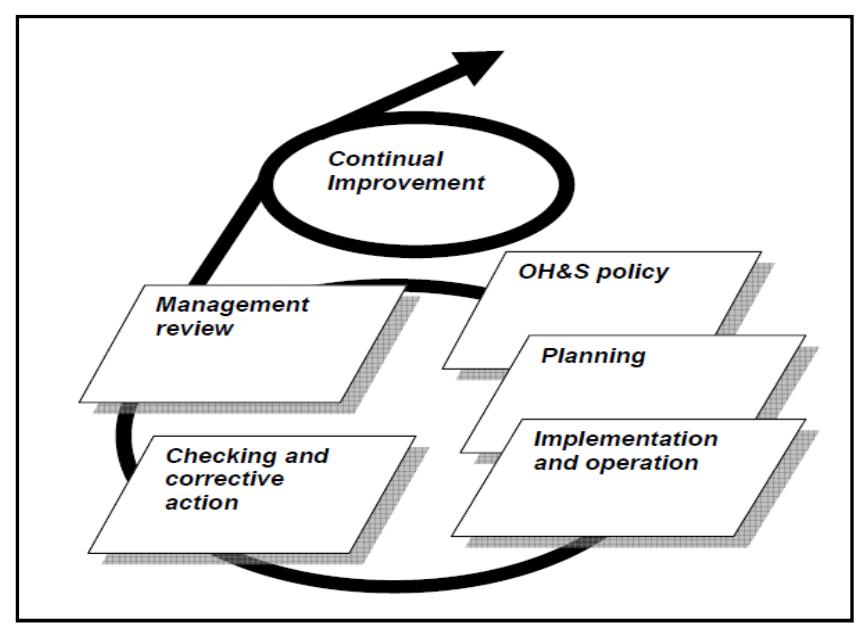

Fig.1. OH\&S management system model for this OHSAS Standard [1]

It is intended to apply to all types and sizes of construction organizations and to accommodate diverse Geographical, Cultural and Social conditions. The overall aim this OHSAS standard is to support and promote good OH\&S practices, in balance with Socio- Economic needs. [7]

\section{1) Approach and Steps to be followed by process of OSH Certification and Testing Regimes (CTRs) [1],}

[6]

It has been developed to be compatible with the ISO 9000(Quality) and ISO 14000(Environment) standards in order to align and integrate Quality, Environment and OHS management systems in the organizations. The OHSAS 18001 certification process is schematically shown in figure.2. In pre-audit review of an organizations application, the certification body conducts a document review and an optional site visit to focus on the scope and planning aspects covering the entire OHSMS. In completion of the pre audit review, the organization undertakes emendation in the system, and once the follow- up actions have been executed, the organization resubmits its revised OHS manuals and procedures for OHSMS audit. The objective of second audit is to confirm that the organization confirms to requirements of the OHSAS 18001. It is a minimum requirement that the organization undertakes one internal audit and management review prior to the OHSMS audit. In case of major nonconformities shall be closed out within the specified time frame, and based on which a recommendation for the award of the certification may be made.

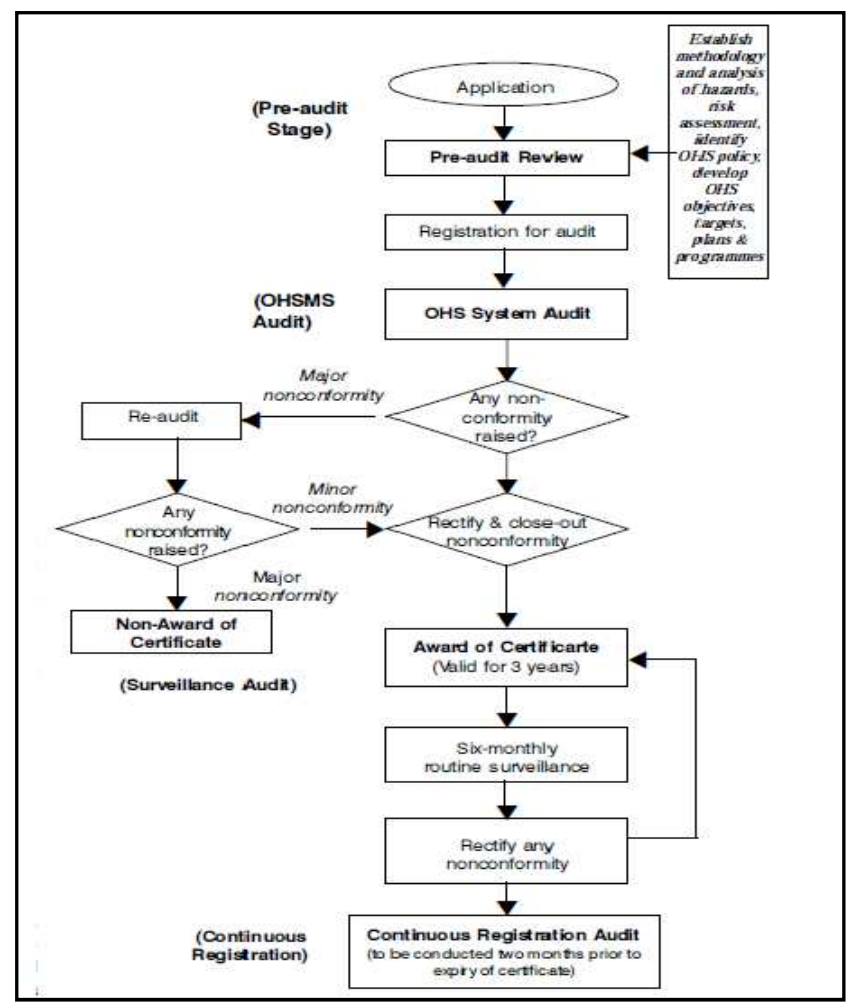

Fig.2: The OHSAS 18001 certification process [4]

During three years valid period of the certificate, at least the annual surveillance audits are to be conducted to ensure that the certified construction organization continues to comply with the OHSAS 18001 requirements. The organization may use combined quality, environment and OHSMS routine surveillance audits to optimize their time and resources. A full reassessment for the renewal of certificate shall be conducted every three years. The certification body shall schedule the reassessment about three months before expiry of the certificate. Upon successful completion of reassessment, the organization will issued a new certificate valid for a future three years. 


\section{HS (G) 65}

The Health and Safety Executive first published "Successful Health and Safety Management", HS(G)65, in 1991 and the revised edition was published in 1997. [7] HS(G)65 takes the "plan-do-check-act" Management Model and translates it into the five key elements of a Successful Health and Safety Management System. The five elements are:
1. Policy
2. Organising
3. Planning and Implementing
4. Measuring Performance
5. Reviewing Performance

These elements are interlinked and are subject to auditing as shown in the HS(G)65 Occupational Health and Safety Management System (OHSMS) Model in figure.3 Below: [4]

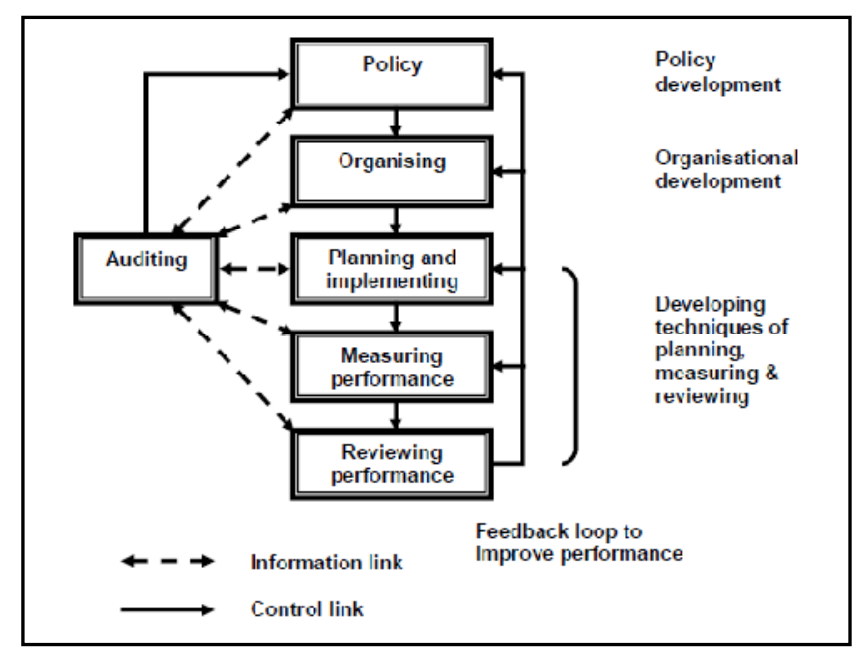

Fig.3. HS (G)65 Model

\section{International Standards: ILO-OSH 2001}

Although there are formal international standards for managing quality (ISO 9000) and environment (ISO 14000), there is no recognised International Organisation Standardisation (ISO) certifiable standard for Occupational Health and Safety Management. ISO has been wary of becoming involved in occupational health and safety. At an ISO Workshop in 1996 it was concluded that the time was not right for an occupational health and safety management standard. Later in 2000 ISO rejected an approach from the International Labour Organisation (ILO) regarding an international standard. Consequently, after it reviewed over twenty national occupational health and safety management systems the ILO developed its own non-certifiable guidance, "Guidelines on occupational safety and health management systems - ILO-OSH 2001". A flow diagram based on the ILO approach is given in Figure.4.

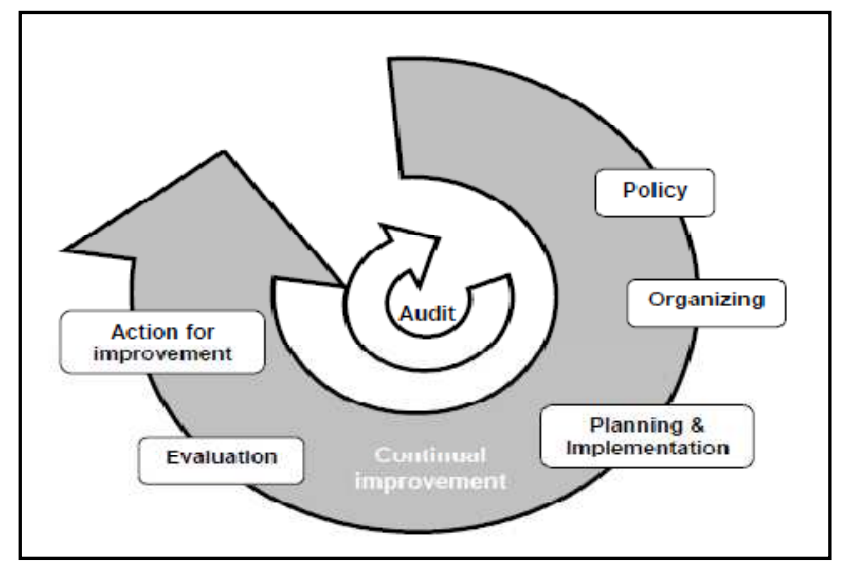

Fig.4. Flow diagram based on the ILO approach [1]

\section{Which system to use for construction projects? [7],}

\section{[2], [3]}

The choice of which system to adopt depends solely on the needs of individual organisations. However, the organisation needs to ensure that their chosen system includes provision for continual improvement, involves stakeholders and auditing and is well documented in order to demonstrate effectiveness. If an organisation already has accreditation under BS EN ISO 9001 and BS EN ISO 14001 it may consider adopting BS OHSAS 18001:2007 as part of an integrated approach. BS OHSAS 18001:2007 is designed to be compatible with these standards for quality and environmental management systems.

The success of the system depends on commitment from all levels and functions of the organization, and especially from top management. An construction organization has the freedom and flexibility to define its boundaries and may choose to implement BS OHSAS 18001: 2007 with respect to entire organization to specific operating units or activities of the organization.

\section{RELATIONSHIP BETWEEN SAFETY AND}

\section{COST- A CASE STUDY}

This work describes an evaluation of the costs of preventing accidents health and the costs of health and safety failures in the construction industry. There are essentially three reasons for the achievement of high standard of health and safety management:

$\checkmark$ First, there are ethical reasons; it is not satisfactorily for employers to place their work people, and people affected by their work, at risk.

$\checkmark$ Secondly, in most states there are statutory legal duties to promote and secure safe working conditions.

$\checkmark$ Thirdly, it is argued that preventing accidents and ill health at work is cost- beneficial. That is to say, any 
money spent on preventing accidents is justified on economic grounds.[5]

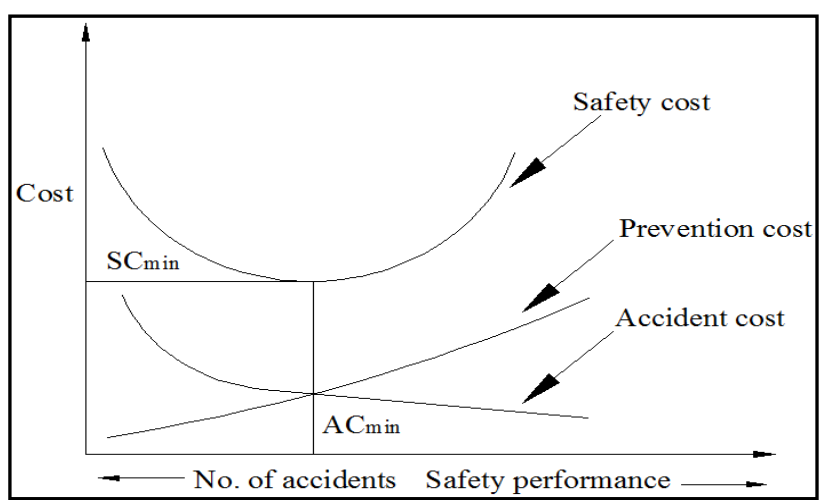

Figure.5. Relationship between Safety and Cost [5]

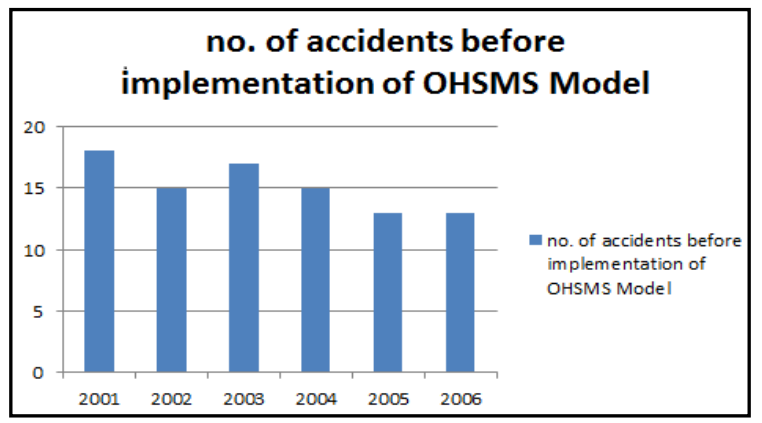

Graph 6.1 no. of accidents before implementation of OHSMS Model

iii) In MICL the cost of project increases up to $6 \%$ to $7 \%$ due to accident before implementation of OHSMS Model.

iv)Implementation cost of OHSMS Model is 3\% of project cost but it saves the increased cost of $6 \%$ to $7 \%$ due to accident. Thus it saves increased cost up to $4 \%$ of total project

\subsection{Salient features of Using OHSMS Model in MICL}

In MICL there are two main aspects for considering the OHSMS Model of OHSAS: 18001 are the number of accidents and the cost of project.

i) The record of accidents that occur in the previous years (2001-2006) before the implementation of OHSMS Model in MICL as shown in graph 6.1.

ii) The record of accidents in the years (2007-2012) after the implementation of OHSMS Model in MICL as shown in graph 6.2 .

By comparing the above two graphs we conclude that the no. of accidents are consistently reduced from the year (20072011) and no accident or zero accident in the year 2012 till now.

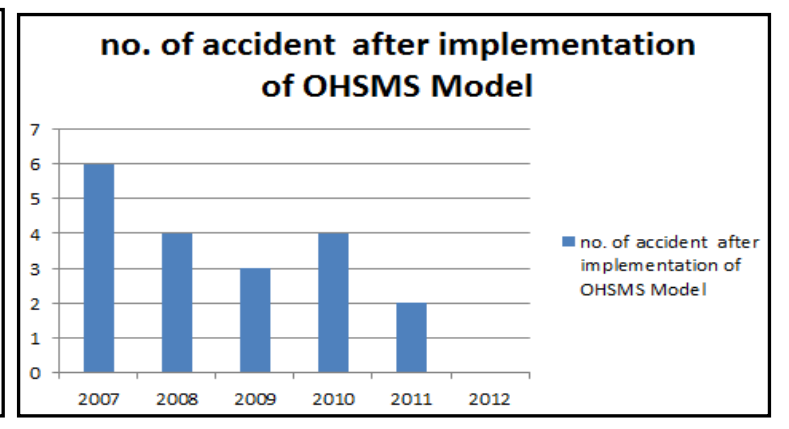

Graph 6.2 no. of accidents after implementation of OHSMS Mode (Source: MICL Safety Dept.)

cost. This is because MICL is using OHSMS Model of OHSAS: 18001 for their BLUE RIDGE project.

\section{CONCLUSIONS}

Table1 showing the cost comparison of Blue Ridge Project- A case study

\begin{tabular}{|c|l|c|}
\hline Sr. No. & \multicolumn{1}{|c|}{ Description } & $\begin{array}{c}\text { Estimated cost } \\
\text { ( in Crores ) }\end{array}$ \\
\hline 1 & The cost of project before implementation of OHSMS Model. & 47.983 \\
\hline 2 & The calculated cost of safety (COS) in Blue Ridge project. & 1.489 \\
\hline 3 & The cost of project after implementation of OHSMS Model. & 49.473 \\
\hline 4 & The cost of safety compared to total cost in percentage. & $3.011 \%$ \\
\hline 5 & The percentage of cost due to accident and fatal injuries. & $6.5 \%$ \\
\hline 6 & The overall Increased Cost of Project (ICP). & 51.102 \\
\hline 7 & The net saving cost of project (NSC). & 3.673 \\
\hline 8 & The net percentage saving cost of project (NPSC). & 3.383 \\
\hline
\end{tabular}


From the above table it can be seen that the benefit- cost ratio (BCR) and net benefit-cost ratio (NBCR) of the Blue Ridge project are 1.123 and 0.123 respectively. After evaluation of Benefit-Cost ratio (BCR) and Net Benefit-Cost ratio (NBCR) of the Blue Ridge project, it can be concluded that the project is economically and financially viable, safe and acceptable that due to implementation of OHSMS Model.

\section{REFERENCES}

[1] Arora Dr. K.C. (2007), "ISO 9000 to OHSAS 18001", S.K. Kataria \& sons Publishing Company Limited.

[2] British Standard, BS OHSAS 18002:2008 "Occupational health and safety management systems - Guidelines for the implementation of BS OHSAS 18001:2007”, British Standards Institution, 2008.

[3] British standard, BS OHSAS 18001: 2007, "Occupational Health and Safety Management systems- Requirements.”, British Standard Institution, 2007.

[4] Dr. Nag. P.K, Dr. Nag. A "A National Priority on Occupational Health and Safety Management System", ICMR BULLETIN, December 2003, Vol.33. No. 1112.

[5] Everett J.G, Frank P.B, (1996), "Costs of Accidents and Injuries to the Construction Industry", ASCE journal, volume 122 .

[6] International Labour Organization, "OSH Management System: A Tool For Continual Improvement”, World Day For Safety and Health at Work, $28^{\text {th }}$ April 2011.

[7] "Occupational Health and Safety Management System", Working party of RSC, EHSC Version 2: 26 Feb.2009. 